\title{
Medical Care Expenditures for Individuals with Prediabetes: The Potential Cost Savings in Reducing the Risk of Developing Diabetes
}

\author{
Tamkeen Khan, PhD, Stavros Tsipas, MA, and Gregory Wozniak, PhD
}

\begin{abstract}
The United States has 86 million adults with prediabetes. Individuals with prediabetes can prevent or delay the development of type 2 diabetes through lifestyle modifications such as participation in the National Diabetes Prevention Program (DPP), thereby mitigating the medical and economic burdens associated with diabetes. A cohort analysis of a commercially insured population was conducted using individual-level claims data from Truven Health MarketScan ${ }^{\circledR}$ Lab Database to identify adults with prediabetes, track whether they develop diabetes, and compare medical expenditures for those who are newly diagnosed with diabetes to those who are not. This study then illustrates how reducing the risk of developing diabetes by participation in an evidencebased lifestyle change program could yield both positive net savings on medical care expenditures and return on investment (ROI). Annual expenditures are found to be nearly one third higher for those who develop diabetes in subsequent years relative to those who do not transition from prediabetes to diabetes, with an average difference of $\$ 2671$ per year. At that cost differential, the 3-year ROI for a National DPP is estimated to be as high as $42 \%$. The results show the importance and economic benefits of participation in lifestyle intervention programs to prevent or delay the onset of type 2 diabetes.
\end{abstract}

Keywords: lifestyle intervention, return on investment, prediabetes, diabetes prevention program

\section{Introduction}

$\mathbf{T}$ HERE ARE 86 MILLION ADULTS with prediabetes in the United States. ${ }^{1}$ These individuals have blood sugar levels that are elevated, but not high enough to be classified as diabetes. It is estimated that within 5 years, up to $25 \%$ of these individuals could develop type 2 diabetes. ${ }^{1}$ In 2012, the estimated annual total economic cost of diabetes was $\$ 245$ billion, with $\$ 176$ billion in direct medical costs and another $\$ 69$ billion in reduced productivity from lost work and wages. These data represent a $41 \%$ increase in costs over the 5-year period from 2007 to $2012 .^{2}$ Costs of diabetes are projected to increase to $\$ 336$ billion by $20344^{2,3}$ Parallel to the rise in the cost of diabetes, the cost of prediabetes increased $74 \%$ to $\$ 44$ billion between 2007-2012. ${ }^{4}$ Prediabetes is associated with greater use of health care services, medications, and other health care products, ${ }^{5,6}$ resulting in increased medical expenditures. ${ }^{4,7}$
Diabetes imposes significant burdens on society in the form of both direct health care costs, and indirect costs including reduced productivity, increased absenteeism, and work loss as a result of diabetes-related disability. ${ }^{2,3,8,9}$ These costs can be mitigated by the National Diabetes Prevention Program (DPP), which has successfully prevented or delayed the onset of diabetes among its participants.

The National DPP is a Centers for Disease Control and Prevention (CDC)-recognized lifestyle change program focused on healthy diet, weight loss, and increased physical activity. ${ }^{10}$ Research shows that with follow-up of 2.8 years, on average, lifestyle interventions reduced the incidence of diabetes by $58 \%$ among individuals with prediabetes, and helped to mitigate the health and economic burdens associated with the disease. ${ }^{1,10,11}$ Additionally, studies show that lifestyle interventions are highly cost-effective when compared to treatment with the drug metformin. ${ }^{12,13}$ Furthermore,

American Medical Association, Chicago, Illinois.

(c) Tamkeen Khan et al. 2017; Published by Mary Ann Liebert, Inc. This article is available under the Creative Commons License CC-BYNC (http://creativecommons.org/licenses/by-nc/4.0). This license permits non-commercial use, distribution and reproduction in any medium, provided the original work is properly cited. Permission only needs to be obtained for commercial use and can be done via RightsLink. 
the Medicare DPP model meets the Centers for Medicare \& Medicaid Services (CMS) standards for improving health and resulted in significant medical cost savings. ${ }^{14}$ In July 2016, CMS announced a proposal to expand the National DPP to Medicare beneficiaries, making it the first preventive service model certified for expansion from the CMS Innovation Center through this process. ${ }^{14,15}$ The American Medical Association (AMA) and CDC have focused efforts toward encouraging physicians to screen and refer individuals with prediabetes to CDC-recognized National DPPs. ${ }^{16}$ These CDC-recognized programs operate under specific standards and procedures to ensure they can achieve the targeted weight loss associated with reductions in the incidence of diabetes. Furthermore, increasing coverage for the National DPP through commercial insurance is one path to decreasing the afflictions associated with diabetes.

The research team is not aware of other research comparing expenditures among newly diagnosed diabetes patients versus prediabetes patients. The team believes this research shows the importance of understanding early identification of the health risk factors and the benefits associated with participation in a National DPP. This study estimates the potential savings in medical care expenditures among commercially insured individuals with prediabetes if they were to participate in a National DPP.

\section{Methods}

First, the at-risk population of individuals is defined as those with prediabetes based on lab test results. Next, the onset of diabetes among this cohort is tracked and differences in spending are compared between individuals with prediabetes who are later diagnosed with diabetes and individuals with prediabetes who are not later diagnosed with the condition. Finally, these estimates of spending differentials and evidence of DPP participation and engagement rates are used to develop an algorithm to estimate the potential cost savings and return on investment (ROI) if diabetes is prevented or delayed in the at-risk population who participate in the program.

\section{The National DPP}

The National DPP is a partnership of public and private organizations providing intensive training in diet, physical activity, and behavior modification. Increased physical activity and weight loss achieved from participation in the program lower the risk of diabetes by improving the body's ability to use insulin and process glucose. ${ }^{17}$ These programs are based on evidence from a randomized clinical trial that showed that people with prediabetes who took part in a structured lifestyle change program cut their risk of developing type 2 diabetes by $58 \% .{ }^{10}$ This risk reduction was a result of a $5 \%$ to $7 \%$ body weight loss through healthier eating and 150 minutes of physical activity a week. These group-based programs are offered both in person and virtually and require a 1-year time commitment with 16 weekly sessions followed by 6 additional monthly sessions. ${ }^{17-19}$ The $5 \%$ weight loss is a minimum target specified in the national standards of the program and further scientific evidence may alter the minimum. For example, a CMS report found that, on average, attending more sessions led to greater weight loss, such that those who completed 16 or more sessions experi- enced weight loss of $6.2 \% .^{14,17,20}$ Staying in the program for the full year is essential to help establish new habits and avoid slipping back into old habits. ${ }^{21}$ The impact of the program can last for years. Even after 10 years, people who completed diabetes prevention lifestyle change programs were one third less likely to develop type 2 diabetes. $^{22}$

\section{Data}

This study utilized individual-level data from the Truven Health MarketScan ${ }^{\circledR}$ Lab Database, which is a 4.4-million person subsample of the Truven Health MarketScan Treatment Pathways. This de-identified data set allowed for a specific focus on the commercially insured population. The database contained integrated claims, lab test results, and enrollment information submitted to Truven under business agreements with more than 150 employers and 200 commercial insurance carriers. Data from 2008-2012 were analyzed for continuously enrolled adults between the ages of 18-64 years in 2008 with an order to screen hemoglobin A1c (HbA1c) in 2009 and a valid result reported within 6 months of the initial laboratory screening. They were selected from patients who met the American Diabetes Associations (ADA) recommendation for HbA1c levels. ${ }^{23}$ Patients excluded were those diagnosed with diabetes or other conditions associated with diabetes (including gestational diabetes), and who were pregnant or taking metformin for at least 6 months prior to the screening.

In the base year, prediabetes was defined as an initial HbA1c test result between $5.7 \%$ and $6.4 \% .^{23,24}$ Other laboratory screens such as a fasting plasma glucose and oral glucose tolerance were excluded from this analysis because patient reports of fasting are often unreliable. The final sample of 8229 adults with prediabetes in the base year was identified after applying the inclusion criteria in Figure 1. Claims for the prediabetes cohort were tracked based on International Classification of Diseases, Ninth Revision codes for primary and secondary diagnosis of diabetes mellitus (all codes with prefix of 250 and 249) and other conditions associated with diabetes (357.2, all codes with prefix of 362 , 366.41 , all codes with prefix of 648).

\section{Medical expenditures estimation}

Total medical expenditures included payments made by both insurance providers and individuals and are reported in nominal US dollars (not adjusted for inflation). A subset of expenditures was studied for primary care physician (PCP) office visits, specialty care office visits, nonphysician office visits, inpatient admissions, other outpatient care, emergency room visits, pharmaceutical prescription drugs, and laboratory tests. ${ }^{25}$ Following the initial HbA1c screen in 2009 (the base year), medical expenditures and diagnoses of diabetes were tracked for 3 years (2010 to 2012). The 3-year time horizon from detection of prediabetes was selected for assessing the net savings and ROI from lifestyle intervention programs because it generally aligns with that of health plans and employers who see employee turnover or change health care plans every few years. ${ }^{26}$

Two tailed $z$ tests were used to compare proportions and 2 -tailed $t$ tests were used for comparisons of means. Statistical significance was defined as $P<0.05$. All analyses were conducted using STATA 13 (StataCorp LP, College Station, TX). 


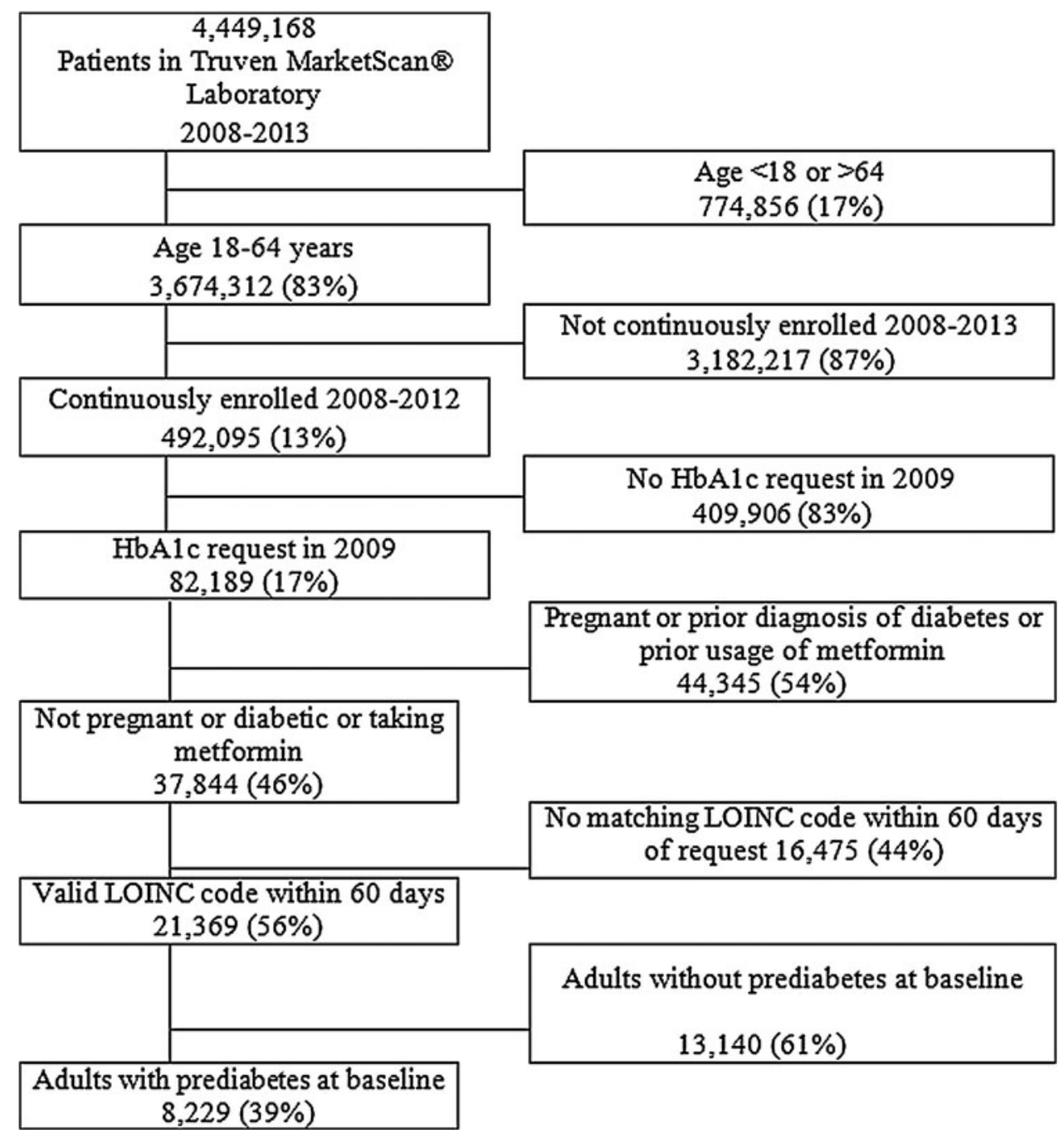

FIG. 1. Study population. HbA1c $<5.7 \%$ is normal; $5.7 \%$ to $6.4 \%$ is consistent with prediabetes, and $>6.4 \%$ is consistent with diabetes. LOINC, logical observation identifiers names and codes.

\section{Net savings and ROI estimations}

To help inform the private payers' decision whether or not to include coverage for the National DPP, results from research on medical expenditures was combined with findings from previous studies ${ }^{10}$ to develop an algorithm to estimate net cost savings and the ROI from enrollment and participation in a National DPP for eligible employees. ${ }^{27}$ First, among the adult population with lab results, approximately $37 \%$ were expected to have prediabetes. ${ }^{1,28}$ Actual prevalence rates may vary by demographics and the lab indicators used, and there is limited research for prevalence rates specific to a 3-year cohort that aligns with the screening criteria used in this study. Next, employers may anticipate a $10 \%$ $50 \%$ enrollment rate in National DPPs, which is a broad range around a $30 \%$ midpoint enrollment rate. ${ }^{29}$ Enrollment is defined as eligible participants attending at least 1 National DPP session. Furthermore, in order to see the health benefits of enrollment in a National DPP, participants must complete the programs. The CDC defines completion rate as the number of enrollees who completed 12 or more sessions ( 9 during the first 6 months and 3 during the second 6 months) divided by the number of eligible enrollees. Alternate definitions of benchmark completion include attending 9 or more sessions of the core 16, attending all sessions among those who attend the initial core sessions, or by using attrition rates. ${ }^{18,29,30}$ Therefore, the available evidence suggests the program completion rate is expected to be $40 \%-70 \% .^{18,29,30}$ Finally, the 3-year cumulative incidence of diabetes among the prediabetes population with and without the lifestyle intervention is used to measure how many individuals completing the lifestyle change program would prevent the onset of diabetes. ${ }^{10}$ It is assumed that the lifestyle change program implementation would be based on programs adopted from National DPPs ${ }^{31}$ and that achieved milestones for enrollment and completion rates are similar to those from prior research.

\section{Results}

\section{Identification of prediabetes}

Baseline descriptive statistics for selected demographic and clinical characteristics for the 8229 commercially insured adults (39\% of the sample) identified with prediabetes 
Table 1. Characteristics of Prediabetes Cohort, and No Diabetes Diagnosis and Diabetes Diagnosis Subgroups Three Years Post HbA1c Screening

\begin{tabular}{|c|c|c|c|c|}
\hline & $\begin{array}{c}\text { Prediabetes } \\
\text { cohort, n (\%) }\end{array}$ & $\begin{array}{l}\text { No diabetes diagnosis, } \\
3 \text { years post HbAlc } \\
\text { screening, } \mathrm{n}(\%)\end{array}$ & $\begin{array}{l}\text { Diabetes diagnosis, } \\
3 \text { years post HbAlc } \\
\text { screening, } \mathrm{n}(\%)\end{array}$ & $\begin{array}{c}\chi^{2 \mathrm{a} / z} \text { ratio }^{\mathrm{b}} \\
\mathrm{P} \text { value }\end{array}$ \\
\hline Total sample & 8229 (100) & $5815(71)$ & 2414 (29) & \\
\hline $\begin{array}{l}\text { Age (years) } \\
18-34 \\
35-44 \\
45-54 \\
55-59 \\
60-64 \\
65+\end{array}$ & $\begin{array}{c}330(4) \\
1315(16) \\
3088(38) \\
1889(23) \\
1462(18) \\
145(2)\end{array}$ & $\begin{array}{r}238(4) \\
985(17) \\
2234(38) \\
1339(23) \\
922(16) \\
97(2)\end{array}$ & $\begin{array}{l}78(3) \\
281(12) \\
809(34) \\
526(22) \\
598(25) \\
122(5)\end{array}$ & $\begin{array}{r}<0.001^{\mathrm{a}} \\
0.052^{\mathrm{b}} \\
<0.001^{\mathrm{b}} \\
<0.001^{\mathrm{b}} \\
0.219^{\mathrm{b}} \\
<0.001^{\mathrm{b}} \\
<0.001^{\mathrm{b}}\end{array}$ \\
\hline $\begin{array}{l}\text { Gender } \\
\text { Female } \\
\text { Male }\end{array}$ & $\begin{array}{l}4206(51) \\
4023(49)\end{array}$ & $\begin{array}{l}2991(51) \\
2824(49)\end{array}$ & $\begin{array}{l}1215(50) \\
1199(50)\end{array}$ & $\begin{array}{l}0.361^{\mathrm{a}} \\
0.361^{\mathrm{b}} \\
0.361^{\mathrm{b}}\end{array}$ \\
\hline $\begin{array}{l}\text { Census region } \\
\text { Northeast } \\
\text { Midwest } \\
\text { South } \\
\text { West } \\
\text { Missing }\end{array}$ & $\begin{aligned} 647(8) \\
761(9) \\
2919(35) \\
3899(47) \\
3(<1)\end{aligned}$ & $\begin{aligned} & 472(8) \\
& 512(9) \\
& 2088(36) \\
& 2740(47) \\
& 3(<1)\end{aligned}$ & $\begin{array}{c}175(7) \\
249(10) \\
831(34) \\
1159(48) \\
0(0)\end{array}$ & $\begin{array}{l}0.077^{\mathrm{a}} \\
0.174^{\mathrm{b}} \\
0.036^{\mathrm{b}} \\
0.199^{\mathrm{b}} \\
0.461^{\mathrm{b}} \\
0.083^{\mathrm{b}}\end{array}$ \\
\hline $\begin{array}{l}\text { Other conditions } \\
\text { Hypertension } \\
\text { Depression } \\
\text { COPD } \\
\text { CHF }\end{array}$ & $\begin{array}{l}\text { utually exclusiv } \\
1732(21) \\
275(3) \\
236(3) \\
105(1)\end{array}$ & $\begin{array}{c}3454(59) \\
378(7) \\
304(5) \\
123(2)\end{array}$ & $\begin{array}{c}1838(76) \\
150(6) \\
201(8) \\
93(4)\end{array}$ & $\begin{array}{r}<0.001^{\mathrm{b}} \\
0.626^{\mathrm{b}} \\
<0.001^{\mathrm{b}} \\
<0.001^{\mathrm{b}}\end{array}$ \\
\hline
\end{tabular}

${ }^{\text {a } P}$ values for univariate chi-square test of independence between characteristics.

${ }^{\mathrm{b}} P$ values for two-tailed $z$ tests to compare proportions between "No diabetes diagnosis" and "Diabetes diagnosis" 3 years post HbA1c screening.

Because of changes in the age groupings, the numbers for individuals with no diabetes diagnosis and diabetes diagnosis may not add up to the number in the original cohort.

$\mathrm{COPD}$, chronic obstructive pulmonary disease; $\mathrm{CHF}$, congestive heart failure.

based on lab results in the base year are shown in Table 1. These screening results aligned well with national estimates. ${ }^{1}$ Among adults between the ages of 18-64 years, a majority (61\%) was between the ages of 45-59 years with the remaining individuals equally distributed between the younger and older age brackets. Additionally, the study cohort was almost evenly distributed by sex. The cohort was more heavily concentrated in the south and west regions of the country; however, sampling weights were not available to adjust for location. A breakdown of other health conditions among this prediabetes cohort is shown in Table 1.

\section{Onset of diabetes}

The onset of diabetes among this cohort of individuals with prediabetes was tracked for 3 years. Further descriptive details for the individuals with no onset of diabetes and those with an onset of diabetes are shown in Table 1. Over 3 years, $29 \%(n=2414)$ of the cohort of adults with prediabetes developed diabetes. Among those who were diagnosed, 53\% were diagnosed in the first year, $28 \%$ in the second year, and $19 \%$ in the third year. Interestingly, this 3year prevalence rate matches the $29 \%$ rate found in the original DPP trial. ${ }^{10}$

The results from the univariate chi-square tests show that among demographic characteristics, only age was associated with the onset of diabetes $(P<0.001)$. Compared to indi- viduals with no diagnoses of diabetes 3 years from the base year, those diagnosed with diabetes were less likely to be between the ages of 35-44 or 45-54 years $(P<0.001)$, and more likely to be between the ages of $60-64$ or $65+$ years $(P<0.001)$. Chronic conditions also were found to be significantly associated with the progression from prediabetes to a diagnosis of diabetes. Hypertension was more prevalent among individuals who developed diabetes than those who did not $(P<0.001)$ (Table 1$)$. There were significant, but only slight differences between the 2 groups in the prevalence of chronic obstructive pulmonary disease $(P<0.001)$ and congestive heart failure $(P<0.001)$. Depression was no more likely among individuals with diabetes than among individuals with prediabetes $(P=0.626)$.

\section{Medical expenditures}

The next part of this study tracked medical expenditures over time and compared the differences in spending between those who developed diabetes and those who did not in the at-risk population identified. Average annual medical expenditures for the prediabetes cohort were $\$ 6837$ (Fig. 2), and were higher among those diagnosed with diabetes in subsequent years compared to those who were not diagnosed. Overall, medical expenditures rose with time and the initial spike in the first year costs for those newly diagnosed with diabetes most likely occurred from poorer health status or 


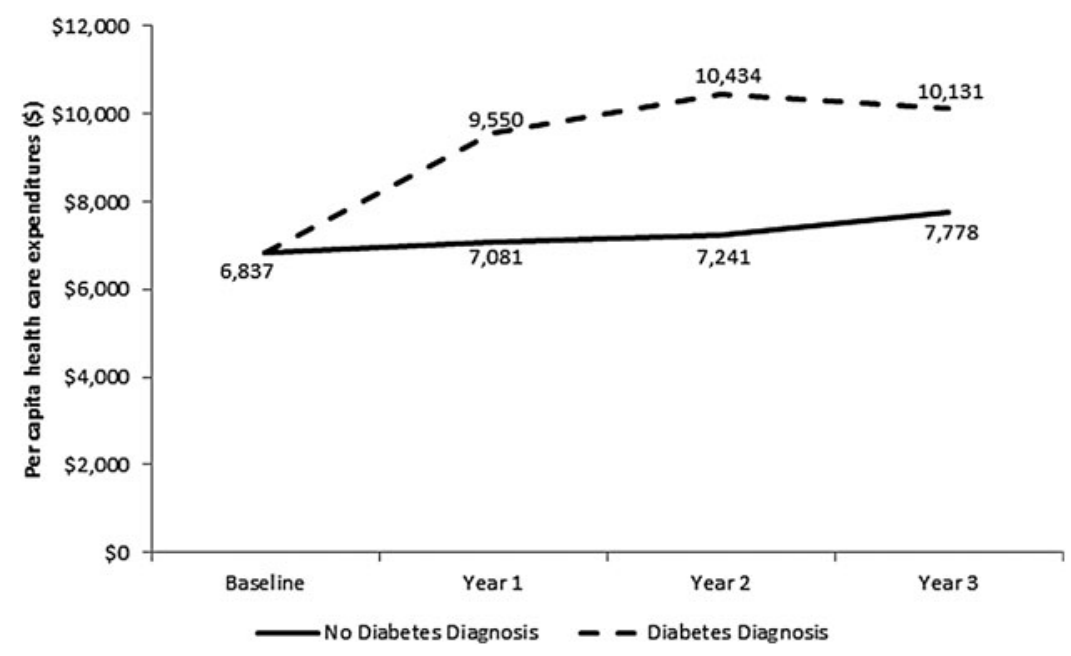

FIG. 2. Progression in average total medical care expenditures for individuals with diabetes diagnosis vs. no diabetes diagnosis, 1 to 3 years post HbA1c screening. These are averages for those who incurred a medical expense.

other utilization of medical care that led to the discovery of diabetes. $^{32,33}$ To measure the differential in spending by prevalence of costly chronic diseases between the 2 groups, propensity score matching was used to identify individuals with similar characteristics to the diabetes group in the nondiabetes group based on demographic and medical claims variables (results not shown). The difference in medical spending in the base year was found to be almost negligible after matching, suggesting that preventing the onset of diabetes can indeed result in medical cost savings $(P>0.05)$. It is important to note that the results do not suggest that the added costs were simply from diagnosing diabetes, but a combination of health factors among these individuals. The annual differential in average medical expenditures was approximately $35 \%, 44 \%$, and $30 \%$ greater among individuals with diabetes in the first year (2010), second year (2011), and third year (2012) following the HbA1c screening, respectively $(P<0.05)$ (Fig. 2).
Figure 3 shows the average medical expenditures for individuals diagnosed with diabetes and individuals who were not diagnosed in the third year after the initial screen by selected medical care categories where the differences in average expenditures were statistically significant $(P<0.05)$ between the 2 groups. For those who incurred a medical expense, the average per capita medical care expenditures for individuals with diabetes were significantly higher for pharmaceuticals $(P<0.05)$, laboratory tests $(P<0.05)$, PCP office visits $(P<0.05)$, and specialty care $(P<0.05)$. Similarly, Figure 4 shows a 3 -year total for cumulative average expenditures for individuals with diagnosed diabetes compared to individuals not diagnosed. The differences in expenditures between the 2 groups of patients was $40 \%$ for PCP office visits (about 2 additional visits per year), $23 \%$ for lab tests, $22 \%$ for prescription drugs, and $10 \%$ for specialty care (all $P<0.05$ ). It is important to note that these were average expenditures specific to each sector and do not

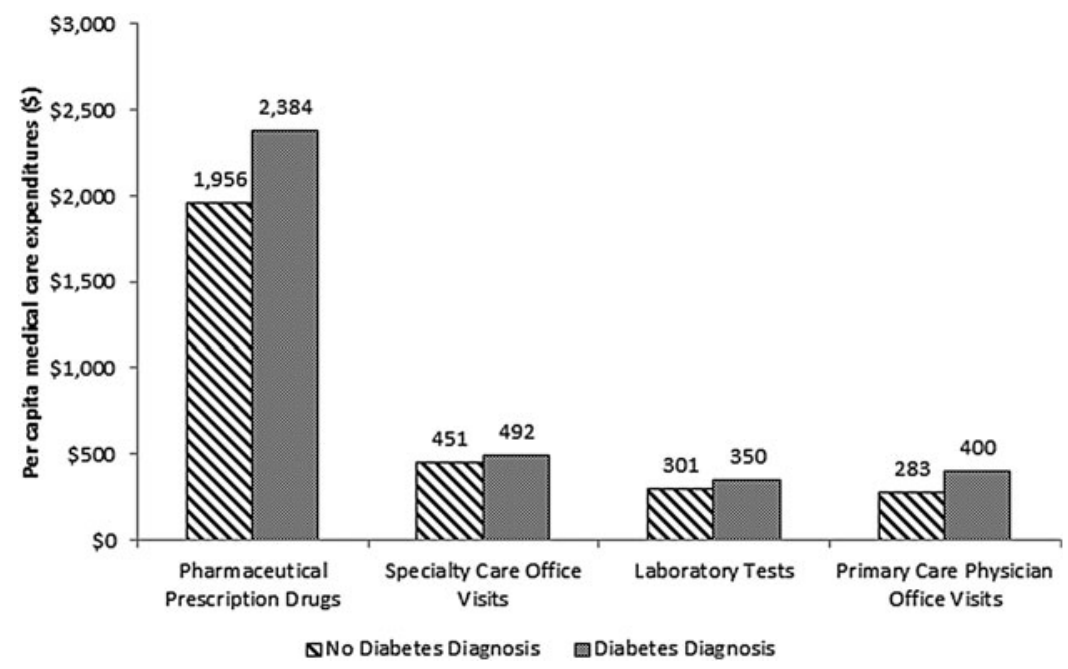

FIG. 3. Average medical care expenditures for individuals with diabetes diagnosis vs. no diabetes diagnosis, 1 to 3 years post $\mathrm{HbA1c}$ screening. Only categories of medical care services with statistically significant differences are reported $(P<0.05)$. These are overall averages for those who incurred a medical expense within each category and do not capture average total expenses. 


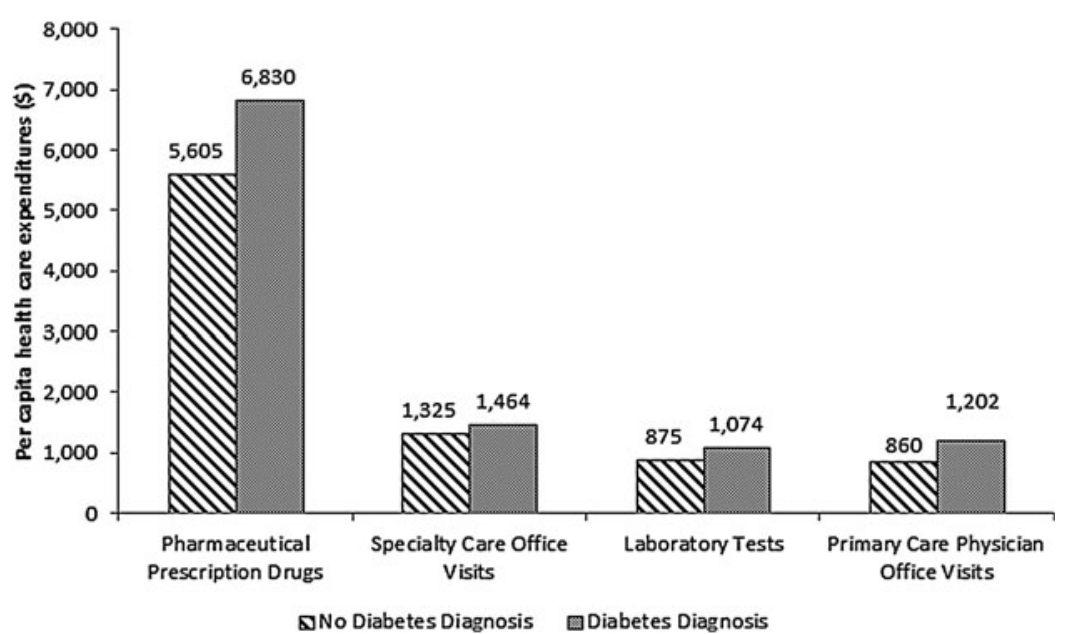

FIG. 4. Average medical care expenditures for individuals with diabetes diagnosis vs. no diabetes diagnosis, cumulative total for 3 years post HbA1c screening. Only categories of medical care services with statistically significant differences are reported $(P \leq 0.05)$. These are overall averages for those who incurred a medical expense within each category and do not capture average total expenses.

represent the total average medical spending trends displayed in Figure 2.

\section{Potential cost savings and ROI}

For simplicity and ease of interpretation, these findings and assumptions were applied to an algorithm based on existing evidence to a sample of 1000 individuals to simulate experience for commercially insured beneficiaries with coverage and access to a CDC-recognized DPP. It is anticipated that 370 individuals $(37 \%)$ would have a lab screening result in the prediabetes range. ${ }^{1,28}$ Of the eligible individuals, 37-185 individuals (10\%-50\%) would enroll in a National DPP, ${ }^{29}$ and 15-130 individuals (40\%-70\%) would successfully complete the program. ${ }^{18,29,30}$ Based on results from this analysis and findings in previous studies, among those who complete, 4-37 individuals (29\%) would be diagnosed with diabetes within 3 years if they had not participated in the intervention. ${ }^{10}$ However, with the intervention, only $2-19$ (14\%) individuals are expected to develop diabetes. ${ }^{10}$ Therefore, the cumulative potential cases of diabetes prevented by the lifestyle program in 3 years would be the differences between the 2 groups, consisting of 2-19 individuals. It is important to note that the core conversion rate of diabetes among those with prediabetes was based on a 3-year cumulative rate. Further, the reduction in incidence rates was based on enrollment and completion of the National DPP research study.

It is estimated that individuals participating in a CDCrecognized National DPP translated to community or primary care settings with explicit adoption of National DPP training materials would be charged $\$ 400-\$ 500$ per person depending on program costs for group-based settings. ${ }^{34}$ For an employer with 1000 beneficiaries with similar risk and severity factors, using these estimates for the 37-185 individuals with prediabetes enrolled in a National DPP, the estimated total program costs would range from $\$ 16,650$ to $\$ 83,250$ ( $\$ 450$ multiplied by the estimated 37 to 185 individuals).
An employer's investment in a lifestyle change program based on these default prevalence, enrollment, completion, and incidence rates would generate potential net savings over 3 years ranging between $-\$ 3131$ to $\$ 35,037$ and a corresponding 3-year ROI ranging from $-19 \%$ to $42 \%$. Assuming the individuals with prediabetes were able to maintain their health status and prevent the progression to diabetes, net savings in the long run would be higher because of lower medical expenditures over time. ${ }^{13}$ In addition, these values are raw estimates that do not include medical insurance components on both ends including premiums, co-pays, and deductibles as well as all payments made by the insurance carrier. Further, it is important to note that this net savings estimate for participation in the National DPP interventions does not include the savings from avoiding lost wages and earnings resulting from increased absenteeism and reduced productivity of the employed population ${ }^{2,35}$ or the benefits from decreasing the loss of quality of life. Overall, just as with the Medicare population, preventing the onset of diabetes among the commercially insured population with prediabetes also can result in improved health outcomes and reduced medical spending.

\section{Discussion}

This study attempted to measure the economic consequences for individuals with prediabetes who were later diagnosed with type 2 diabetes to better understand the benefits associated with participation in a National DPP. This study found that among a cohort of commercially insured adults, those with prediabetes and later diagnosed with diabetes had medical expenditures nearly one third higher than those who were not later diagnosed. The estimated annual differential in spending was \$2671, which was smaller than previously published estimates of the cost of diabetes for a population with commercial coverage ranging from $\$ 7300$ in 2009 to $\$ 10,694$ in $2013 .^{36,37}$ This is because the comparison group for the estimates in the present study was a cohort of individuals with a prediabetes lab value in the base year, whereas 
previous estimates of medical spending for diabetes used all patients without a diagnosis of diabetes. Furthermore, previous research has shown prediabetes is associated with higher use of health care services, medications, and other health care products. ${ }^{5,6}$ Therefore, all of these individuals were likely to have higher medical expenditures compared to a subpopulation with no indication of prediabetes. ${ }^{4,7}$ Although prescription drug spending was highest for all individuals with prediabetes, individuals who developed diabetes faced significantly higher expenditures for prescription drugs, specialty care, lab tests, and PCP office visits.

Interestingly, the estimates from this study align well with those of the Office of the Actuary that suggest $\$ 2650$ in cost savings for Medicare beneficiaries over 15 months by offering a DPP. ${ }^{14,20}$ These results help to build the case for participation in an evidence-based National DPP to prevent or delay the development of diabetes and mitigate the economic burden of the disease. The algorithm applied here suggests that net savings and positive ROI can be attained for the commercially insured population from lifestyle interventions. Furthermore, if the savings in medical care expenditures from completion of a National DPP can be sustained over the long term by maintaining a healthy diet, weight loss, and increased physical activity, the ROI estimates presented here are likely to be underestimated.

Improvements in the ROI and increases in net savings can be achieved through program modifications including reducing program cost, raising patient engagement, and incentivizing program completion. Because the $\$ 450$ used is an average estimate cost of an on-site National DPP, negotiating lower costs per participant can lower the overall costs of offering the program and yield higher net savings. Another primary driver behind the net savings and ROI is the program completion rate. Utilizing incentives to increase completion rates or utilizing engagement assessment to identify patients most likely to complete the National DPP will improve net savings and ROI. Performance-based payments tied to enrollment, program completion, and clinical outcomes (such as weight loss and reductions in HbA1c levels) also have been used as incentives for DPP providers. ${ }^{38}$ Behavioral economics suggests individuals are attracted by immediate rather than delayed benefits. Therefore, motivating completion of a National DPP can occur by providing smaller tangible incentives and encouragement at each weekly visit, rather than only at the end of the program. Evidence from other employee health promotion programs shows that financial rewards or penalties designed within smoking cessation, weight loss, and medication adherence programs led to better compliance. ${ }^{39}$

This study has certain limitations. First, the rates of onset of diabetes applied here may differ from other patient populations, especially in the first year. Given the nature of administrative data, the research team was unable to identify the specific reason for ordering the blood test, but these patients may have had some underlying health concerns that prompted the HbA1c screen. Therefore, it is important to note that a different population of commercially insured individuals with prediabetes may experience different rates of diabetes onset in the course of 3 years. Second, although the benefits of stratifying and controlling the analysis by specific characteristics are recognized, reliable results with the current sample sizes were not obtained. In the future, the research team hopes to expand on this foundation of work with a richer data set and a multivariate framework. Finally, the actual milestones from DPP participation may vary from what is in the literature. Therefore, reasonable ranges were provided to offer the best proxy for these milestones.

The AMA and CDC have promoted the need for expanded coverage and access to National DPP programs to reduce the risk of people with prediabetes developing diabetes. ${ }^{16}$ Although there are pockets of coverage for the National DPP, a national strategy that includes private and public programs targeting the 86 million US adults with prediabetes remains missing. The recent CMS certification for expansion of the program opens up opportunities for further funding of health promotion programs to improve health and save money. Translating this expansion to the commercial insurance sector could stimulate further improvements in health for a large fraction of the population by preventing diabetes and other chronic health conditions. The success of these community-based preventive efforts would reduce medical spending, improve productivity, and potentially earn positive ROI.

\section{Author Disclosure Statement}

The authors declared that there are no conflicts of interest with respect to the research, authorship, and/or publication of this article. The authors received no financial support for this article.

\section{References}

1. Centers for Disease Control and Prevention. National Diabetes Statistics Report, 2014: Estimates of Diabetes and Its Burden in the United States. www.cdc.gov/diabetes/pubs/ statsreport14/national-diabetes-report-web.pdf Accessed March $1,2015$.

2. American Diabetes Association. Economic costs of diabetes in the US in 2012. Diabetes Care 2013;36:1033-1046.

3. Huang ES, Basu A, O'Grady M, Capretta JC. Projecting the future diabetes population size and related costs for the US. Diabetes Care 2009;32:2225-2229.

4. Dall TM, Yang W, Halder P, et al. The economic burden of elevated blood glucose levels in 2012: diagnosed and undiagnosed diabetes, gestational diabetes mellitus, and prediabetes. Diabetes Care 2014;37:3172-3179.

5. Nichols GA, Brown JB. Higher medical care costs accompany impaired fasting glucose. Diabetes Care 2005;28: 2223-2229.

6. Zhang Y, Dall TM, Chen Y, et al. Medical cost associated with prediabetes. Popul Health Manag 2009;12:157-163.

7. Dall TM, Zhang Y, Chen YJ, Quick WW, Yang WG, Fogli J. The economic burden of diabetes. Health Aff (Millwood) 2010;29:297-303.

8. Brown JB, Nichols GA, Glauber HS, Bakst AW. Type 2 diabetes: incremental medical care costs during the first 8 years after diagnosis. Diabetes Care 1999;22:1116-1124.

9. Ramsey S, Summers KH, Leong SA, Birnbaum HG, Kemner JE, Greenberg P. Productivity and medical costs of diabetes in a large employer population. Diabetes Care 2002;25:23-29.

10. Knowler WC, Barrett-Connor E, Fowler SE, et al. Reduction in the incidence of type 2 diabetes with lifestyle intervention or metformin. N Engl J Med 2002;346:393-403.

11. Dall TM, Storm MV, Semilla AP, Wintfeld N, O'Grady M, Narayan KMV. Value of lifestyle intervention to prevent diabetes and sequelae. Am J Prev Med 2015;48:271-280. 
12. Herman WH, Hoerger TJ, Brandle M, et al. The costeffectiveness of lifestyle modification or metformin in preventing type 2 diabetes in adults with impaired glucose tolerance. Ann Intern Med 2005;142:323-332.

13. The Diabetes Prevention Program Research Group. The 10year cost-effectiveness of lifestyle intervention or metformin for diabetes prevention: an intent-to-treat analysis of the DPP/DPPOS. Diabetes Care 2012;35:723-730.

14. Spitalnic P. Certification of Medicare Diabetes Prevention Program. 2016. https://www.cms.gov/Research-StatisticsData-and-Systems/Research/ActuarialStudies/Downloads/ Diabetes-Prevention-Certification-2016-03-14.pdf. Accessed March 30, 2016.

15. Centers for Medicaid \& Medicare Services. Medicare Diabetes Prevention Program Expansion. 2016. https://www .cms.gov/Newsroom/MediaReleaseDatabase/Fact-sheets/2016Fact-sheets-items/2016-07-07.html. Accessed January 8, 2016.

16. American Medical Association, Centers for Disease Control and Prevention. Prevent Diabetes STAT. http://www.amaassn.org/sub/prevent-diabetes-stat/for-health-care-professionals .html. Accessed April 1, 2016.

17. The Diabetes Prevention Program Research Group. The Diabetes Prevention Program (DPP) description of lifestyle intervention. Diabetes Care 2002;25:2165-2171.

18. Sepah SC, Jiang L, Peters AL. Translating the Diabetes Prevention Program into an online social network: validation against CDC standards. Diabetes Educ 2014:40:435443.

19. Su W, Chen F, Dall TM, Iacobucci W, Perreault L. Return on investment for digital behavioral counseling in patients with prediabetes and cardiovascular disease. Prev Chronic Dis 2016;13:E13.

20. RTI International. Evaluation of the Health Care Innovation Awards: Community Resource Planning, Prevention and Monitoring, Annual Report 2015. https://innovation.cms. gov/Files/reports/hcia-ymcadpp-evalrpt.pdf. Accessed June $1,2016$.

21. Centers for Disease Control and Prevention. Lifestyle change program details. 2016. http://www.cdc.gov/diabetes/ prevention/lifestyle-program/experience/index.html. Accessed June 1, 2016.

22. Centers for Disease Control and Prevention. Research-based prevention program. 2016. http://www.cdc.gov/diabetes/ prevention/prediabetes-type2/preventing.html. Accessed June 1, 2016.

23. American Diabetes Association. Standards of medical care in diabetes-2013. Diabetes Care 2013;36(suppl 1):S11.

24. James C, Bullard KM, Rolka DB, et al. Implications of alternative definitions of prediabetes for prevalence in US adults. Diabetes Care 2011;34:387-391.

25. Truven Health Analytics. MarketScan Treatment Pathways User Guide v 3.0. 2013. https://marketscan.truvenhealth. com/marketscanportal/portal.aspx. Accessed March 1, 2015.

26. Chatterjee R, Narayan KM, Lipscomb J, Phillips LS. Screening adults for pre-diabetes and diabetes may be costsaving. Diabetes Care 2010;33:1484-1490.

27. American Medical Association. AMA DPP Cost Savings Calculator. 2015. https://ama-roi-calculator.appspot.com. Accessed December 31, 2015.
28. Bullard KM, Saydah SH, Imperatore G, et al. Secular changes in US prediabetes prevalence defined by hemoglobin A1c and fasting plasma glucose National Health and Nutrition Examination Surveys, 1999-2010. Diabetes Care 2013;36:2286-2293.

29. America's Health Insurance Plans. Health Plans Preventing Diabetes and Improving Well-Being. 2016. www.ahip.org/ prediabetes. Accessed December 15, 2016.

30. Ali MK, Echouffo-Tcheugui JB, Williamson DF. How effective were lifestyle interventions in real-world settings that were modeled on the Diabetes Prevention Program? Health Aff (Millwood) 2012;31:67-75.

31. Centers for Disease Control and Prevention. Centers for Disease Control and Prevention Diabetes Prevention Recognition Program Standards and Operating Procedures. 2015. www.cdc.gov/diabetes/prevention/pdf/dprp-standards .pdf. Accessed June 1, 2016.

32. Centers for Medicaid \& Medicare Services. National Health Expenditure Projections 2012-2022. 2012. https:// www.cms.gov/research-statistics-data-and-systems/statisticstrends-and-reports/nationalhealthexpenddata/downloads/ proj2012.pdf. Accessed June 1, 2016.

33. Keehan SP, Cuckler GA, Sisko AM, et al. National health expenditure projections, 2014-2024: spending growth faster than recent trends. Health Aff (Millwood) 2015;34: 1407-1417.

34. Li R, Qu S, Zhang P, et al. Economic evaluation of combined diet and physical activity promotion programs to prevent type 2 diabetes among persons at increased risk: a systematic review for the Community Preventive Services Task Force. Ann Intern Med 2015;163:452-460.

35. Goetzel RZ, Long SR, Ozminkowski RJ, Hawkins K, Wang S, Lynch W. Health, absence, disability, and presenteeism cost estimates of certain physical and mental health conditions affecting US employers. J Occup Environ Med 2004;46:398-412.

36. Vojta D, De Sa J, Prospect T, Stevens S. Effective interventions for stemming the growing crisis of diabetes and prediabetes: a national payer's perspective. Health Aff (Millwood) 2012;31:20-26.

37. Health Care Cost Institute. Per Capita Health Care Spending on Diabetes: 2009-2013. 2015. http://www.healthcostinstitute .org/issue-brief-capita-health-care-spending-diabetes-20092013. Accessed July 30, 2015.

38. Ackermann RT, Holmes AM, Saha C. Designing a natural experiment to evaluate a national health care community partnership to prevent type 2 diabetes. Prev Chronic Dis 2013;10:E12.

39. Volpp KG, Asch DA, Galvin R, Loewenstein G. Redesigning employee health incentives-lessons from behavioral economics. N Engl J Med. 2011;365:388-390.

Address correspondence to: Tamkeen Khan, PhD American Medical Association 330 North Wabash Avenue, Suite 39300 Chicago, IL 60611

E-mail: tamkeen.khan@ama-assn.org 